\title{
Giant congenital melanocytic nevi: 40 years of experience with the serial excision technique*
}

\author{
Lais de Abreu Mutti ${ }^{1}$ \\ João Marcos Goes de Paiva ${ }^{1}$ \\ Mauro Yoshiaki Enokihara ${ }^{3}$
}

\author{
Marta Regina Machado Mascarenhas ${ }^{1}$ \\ Ronaldo Golcman ${ }^{2}$ \\ Benjamin Golcman ${ }^{2}$
}

DOI: http:/ / dx.doi.org/10.1590/abd1806-4841.20174885

\begin{abstract}
Although giant congenital melanocytic nevus is a rare lesion, it causes significant deformity and carries a risk of malignant degeneration. Different surgical techniques for the lesion removal are described, including serial resection, resection with skin grafting, and resection and coverage with expanded skin flap (skin expanders). The aim of this study is to report the author's 40 years of experience with cases requiring at least 4 serial excisions to complete the treatment. Serial resection is an effective, safe, and simple technique that requires a lot of patience. Treatment often results in a single linear scar, requires no donor sites, nor large flaps. It is not subject to potencial complications of expanders and avoid aesthetic deformities depending on the location.
\end{abstract}

Keywords: Cutaneous neoplasias; Nevi and melanomas; Pigmented nevus

\section{INTRODUCTION}

Large/giant congenital melanocytic nevus (GCMN) is generally defined as melanocytic lesions present at birth that reach at least $20 \mathrm{~cm}$ in diameter in adulthood. ${ }^{1,2}$

The risk of malignant degeneration (melanoma), the difficulty of clinical follow-up, and the major psychosocial impact on patients and family members due to the often unsightly appearance often lead us to opt for resection of lesions. ${ }^{3}$

Some surgical options described for GCMN treatment include serial resection, skin grafts, and the use of tissue expanders. ${ }^{2,4}$ The use of large grafts or tissue expanders is a common choice when more than three stages are required for resection. ${ }^{4,5}$ Expander treatment, however, may take 3-6 months depending on the area to be reconstructed. During this period, the expander generates an uncomfortable and unsightly protuberance, and requires multiple injections for expansion..$^{2,5,6}$

The objective of this report is to share the author's experience with serial excisions even when more than three stages were necessary to treat GCMN.

\section{CASE REPORTS}

We describe the author's 40 years of experience with serial excision of GCMN that requires at least four steps to a complete removal.

The technique includes local or general anesthesia, depending on the patient's age, lesion size, and location. The central area of the lesion is excised in its total depth - including all the subcutaneous tissue or part of it in thicker subcutaneous areas with exten- sive detachment. After the evaluation of how much the skin moves up to the incision line by using tension and the splitting technique, excisional surgery of the advanced tissue is performed, avoiding tension (Figure 1). How much of a nevus can be excised in one operation depends on the elasticity of the surrounding tissue. The lesion is sutured with internal and external stitches. Resections are spaced by sufficient time to allow relaxation of the tissue and the maturation of the scar, which usually takes 3-6 months. In the present study, longer intervals were required due to the difficulty of getting an appointment under the public health system.

In order to minimize the final length of the scar, all apices of the ellipses should be positioned within the lesion before the final excision. ${ }^{7}$ Intralesional excision is particularly important for pigmented lesions since it prevents pigmented cells of the nevus from being transported by the suture to the normal skin. ${ }^{8}$

More than 30 lesions were removed using this technique in both children only a few months old and adults up to 65 years, with a predominance of pediatric patients. We treated lesions on the face, trunk, lower limbs, and upper limbs, with good cosmetic results, without complications, and with a high degree of satisfaction of patients and family members (Figures 2-6). No dehiscence or infection was observed in any of the cases. Up to 11 steps were necessary in a patient. ${ }^{7}$ Three patients had melanoma: two at the time of the first excision, both on the face, and another in the third operative section, when a nodule appeared on the scalp.

Received on 29.06.2015

Approved by the Advisory Board and accepted for publication on 21.01.2016

* Work performed at Dermatologic Department at Universidade Federal de São Paulo (UNIFESP) - São Paulo (SP), Brazil.

Financial support: none.

Conflict of interest: none.

Dermatologic Surgery Center at Universidade Federal de São Paulo (UNIFESP) - São Paulo (SP), Brazil.

School of Medicine at Universidade de São Paulo (USP) - São Paulo (SP), Brazil.

Dermatologic Department at Universidade Federal de São Paulo (UNIFESP) - São Paulo (SP), Brazil.

(C2017 by Anais Brasileiros de Dermatologia 

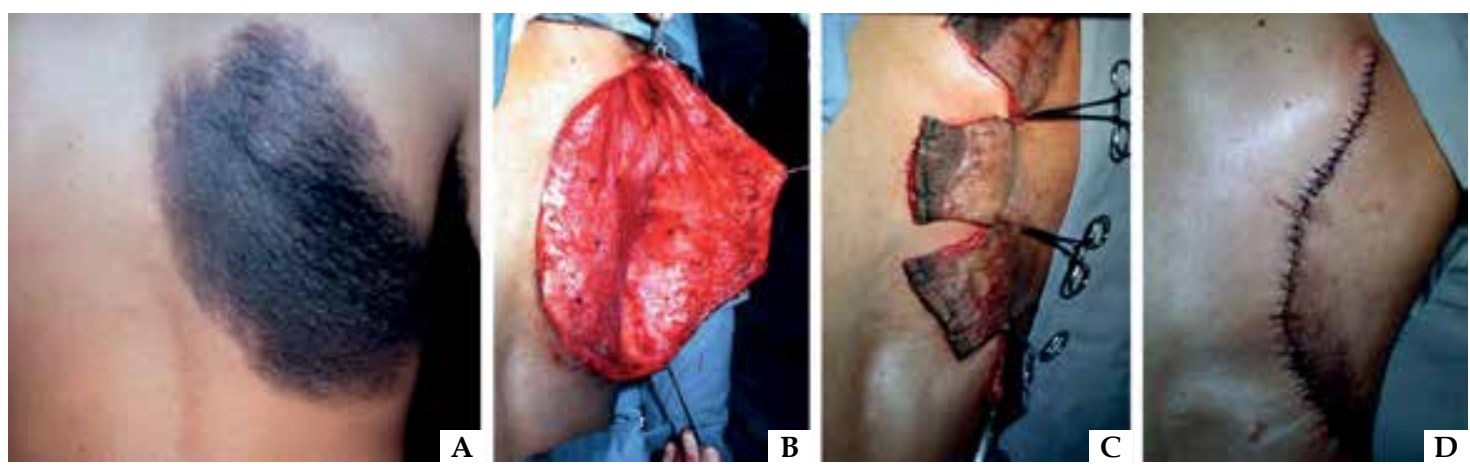

Figure 1: Serial excision of congenital melanocytic nevus on the back. A: Preoperative appearance; B: partial excision of the lesion in its whole depth with a large detachment to allow tissue advancement; C: splitting technique to evaluate how much tissue advances without tension. Under this technique, the detached tissue is advanced and cut perpendicularly until it reaches the incision line of the lesion without tension, thereby, delimiting the amount of tissue that can be removed to close with primary suturing. In this case, because it was a large lesion, more than one splitting was necessary; D: result after resection of advanced tissue and suture
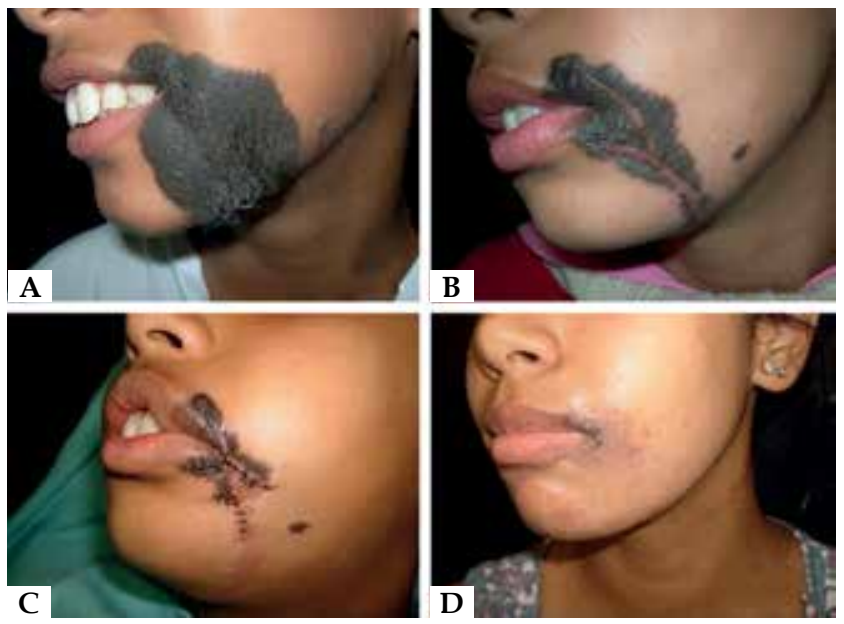

Figure 2: Serial excision of congenital melanocytic nevus in the left perilabial region. A: Preoperative appearance with 12 years; B: after the first excision; C: after the third excision; D: result after 5 stages

\section{DISCUSSION}

Congenital melanocytic nevi (CMN) is a risk factor for the development of melanoma. However, the actual incidence of malignancy is still controversial. In a systematic review, the incidence of melanoma in the studies ranged from $0.05-10.7 \% .^{9}$ Data from these studies revealed that $0.7 \%$ developed melanoma, with an average age of 15.5 years. The risk of developing melanoma depends largely on the nevus size, with a $2.5 \%$-incidence in cases of GCMN, and about three-thirds of melanomas occurring in nevi with more than $40 \mathrm{~cm}$. $67 \%$ of cases revealed primary melanoma within the nevus; $14 \%$, metastatic melanoma with unknown primary site; and $8 \%$, extracutaneous melanoma. ${ }^{9}$ Although surgery does not reduce the risk of extracutaneous melanoma, removal of melanocytic cells appears to reduce the risk of developing melanoma within the lesion. ${ }^{3.9}$

Serial excision is an effective strategy for the treatment of congenital melanocytic nevus and shows advantages when compared to other surgical techniques. The technique is simple, procedure time is short, and, in most cases, surgery can be performed without hospitalization. Better patient tolerance is observed. Recovery is rapid with
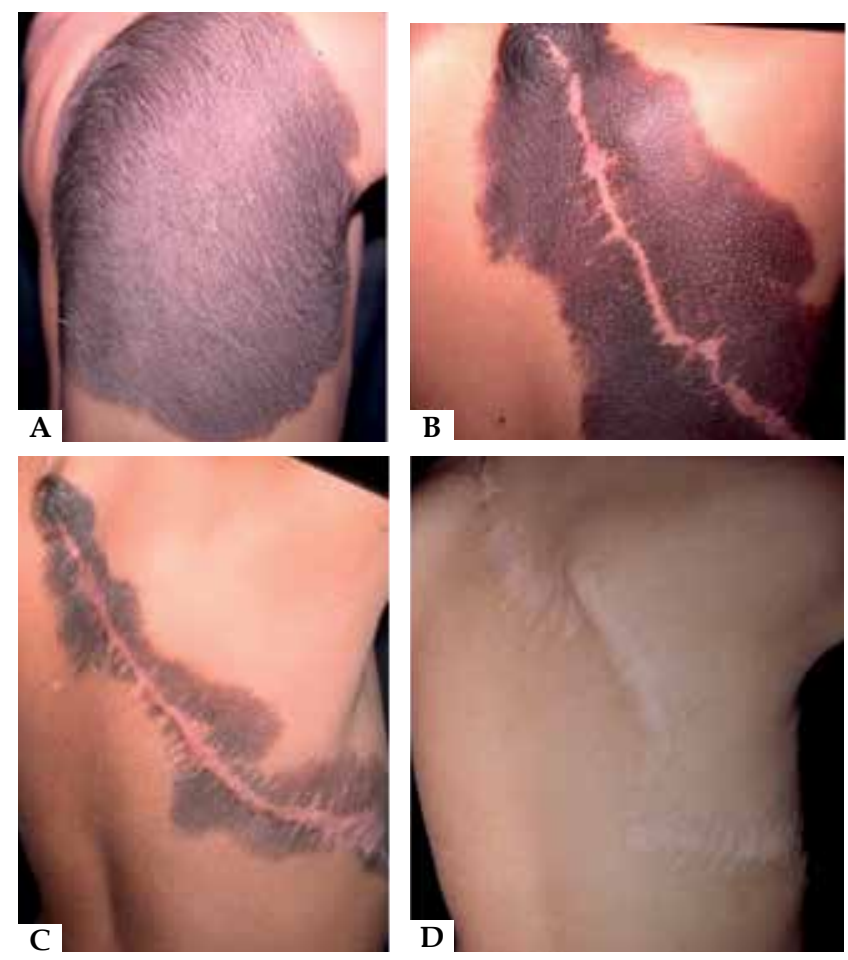

Figure 3: Serial excision of congenital melanocytic nevus on the back. A: Preoperative appearance with 17 years; B: after the first excision; C: after the third excision; D: result after 5 stages

little pain, and complications such as infection or suture dehiscence are rare and do not compromise future approaches or the end result. If dehiscence or infection occurs in skin grafts or tissue expanders, the consequences can be significantly more problematic. Although studies describe a complication rate of $4 \%$ in serial excision, no complications were reported in our experience. ${ }^{4}$ Complication rates with expanders, however, range from $13 \%-20 \%$, such as pain during the expansion, poor positioning, extrusion, and infection. . $^{510}$

Even if the complete removal of the nevus with multiple resections is not often possible, the best aesthetic result and the psychosocial impact justify the choice of this technique. The end result 

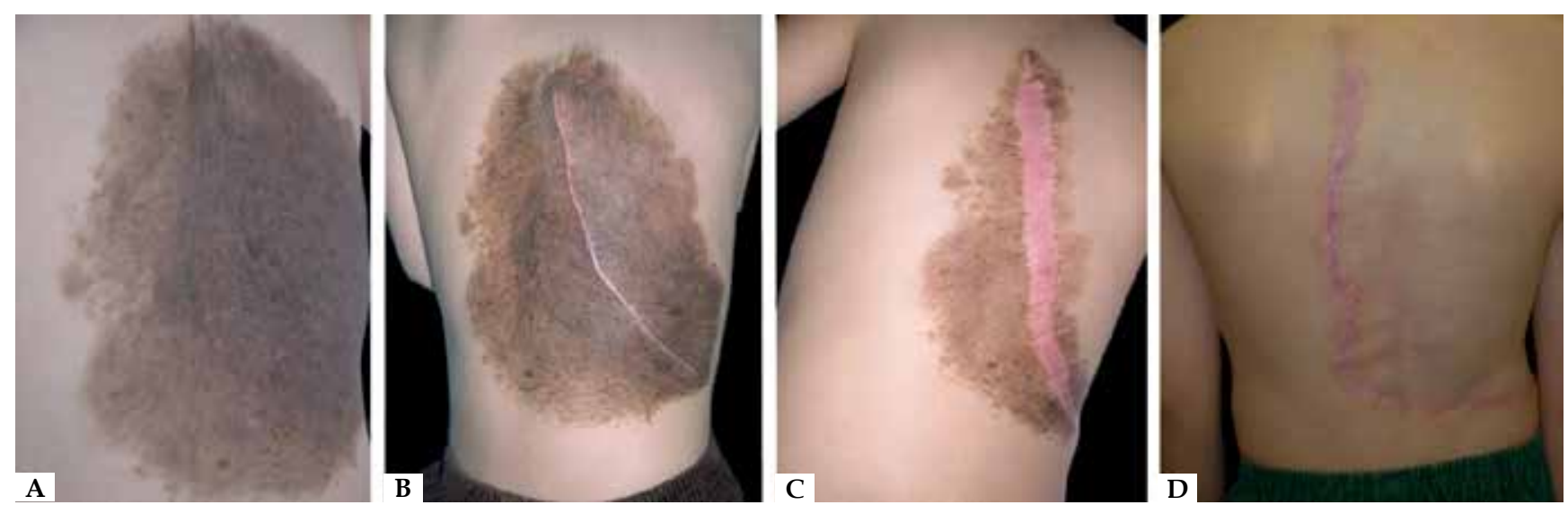

FigURE 4: Serial excision of congenital melanocytic nevus on the back. A: preoperative appearance with 15 years; B: after the first excision; C: after the third excision; D: result after 5 stages
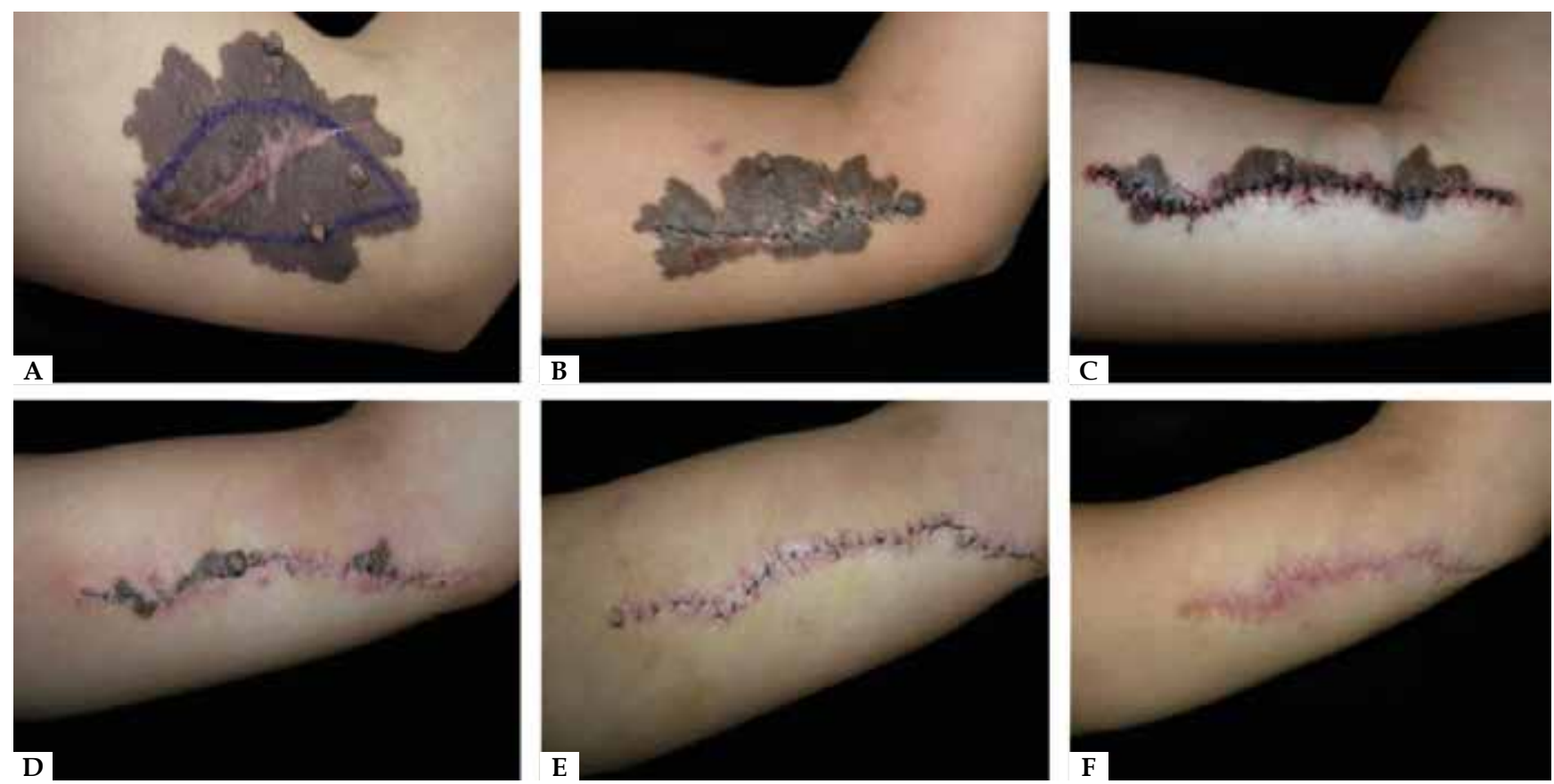

Figure 5: Serial excision of congenital melanocytic nevus on the arm. A: preoperative marking before the second stage; B: after the second excision; C: after the third excision; D: After the fourth excision; E: after the fifth excision; F: result 4 months after the last excision
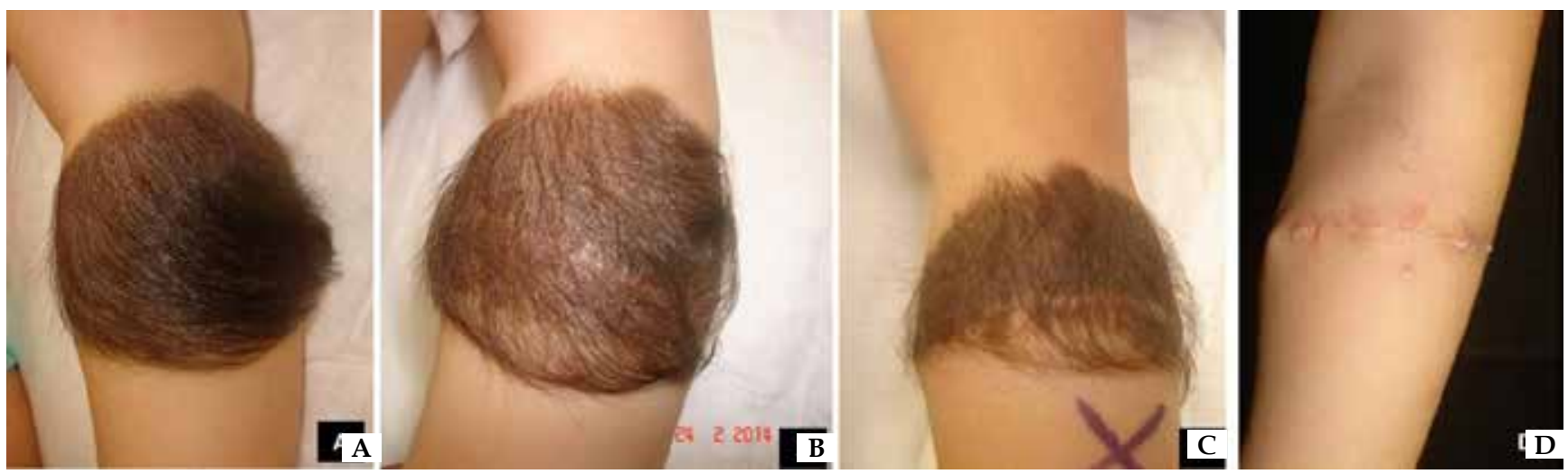

Figure 6: Serial excision of congenital melanocytic nevus on the forearm. A: Preoperative appearance with 1 year; B: after the first excision; C: after the second excision; D: result after 4 stages 
is a linear scar, more desirable than the multiple and extensive scars left by expanders and flaps, or different color and contour caused by grafts (besides the scar in the donor area in the latter case). ${ }^{4}$

Despite the advantages of serial excision, this technique is not the best option for some anatomical areas. Some examples include eyelids, perioral or fold areas, or any other area where there may be a functional alteration due to extensive tissue displacement and tissue traction, which requires reconstruction with skin grafts. ${ }^{2}$ Large nevi on the scalp in older children are better handled with expanders for the reconstruction of the hairy area of the scalp. If normal skin is not present on both sides of a GCMN lesion to advance toward the center (e.g. circular lesions on extremities), skin grafting or tissue expanders can be more appropriate choices. ${ }^{4}$

The benefits of serial excision as well as the lower risk of complications compared to any other reconstructive method make this the author's technique of choice for addressing GCMN. Such an approach requires great patience on the part of both surgeon and patient and understanding on the part of family members, for it can take a few years before the complete removal of the $\mathrm{CMN}$.

\section{REFERENCES}

1. Viana AC, Gontijo B, Bittencourt FV. Giant congenital melanocytic nevus. An Bras Dermatol. 2013;88:863-78.

2. Carneiro Junior LVF, Aguiar LFS, Pitanguy I. Surgical Treatment of giant melanocytic nevi. Rev Bras Cir Plast. 2011;26:198-204.

3. Marghoob AA, Agero AL, Benvenuto-Andrade C, Dusza SW. Large congenital melanocytic nevi, risk of cutaneous melanoma, and prophylactic surgery. J Am Acad Dermatol. 2006;54:868-70.

4. Hassanein AH, Rogers GF, Greene AK. Management of challenging congenital melanocytic nevi: Outcomes study of serial excision. J Pediatr Surg. 2015;50:613-6.

5. Arneja JS, Gosain AK. Giant congenital melanocytic nevi. Plast Reconstr Surg. 2009;124:1e-13e.

6. Bin S, Yuanbo L, Ji J, Shan Z. Preexpanded Pedicle Medial Arm Flap: An Alternative Method of Massive Facial Defect Reconstruction. Aesthetic Plast Surg. 2011;35:946-52.

7. Golcman B, Friedhofer H, Anger M, Golcman R. Giant congenital composite melanocytic nevus on the face and scalp: treatment by multiple resections and grafting. J Dermatol Surg Oncol. 1980;6:130-2.

8. Altchek ED. A technical consideration in the serial excision of a nevus. Plast Reconstr Surg. 1980;66:849-50.

9. Krengel S, Hauschild A, Schäfer T. Melanoma risk in congenital melanocytic naevi: a systematic review. Br J Dermatol. 2006;155:1-8.

10. LoGiudice J, Gosain AK. Pediatric tissue expansion: indications and complications. J Craniofac Surg. 2003;14:866-72. \begin{tabular}{l}
\hline MAILING ADDRESS: \\
Lais de Abreu Mutti \\
Rua Borges Lagoa, 508 \\
Vila Clementino \\
04038-000 - São Paulo - SP \\
Brazil \\
E-mail: laisabreu@yaho.com.br
\end{tabular}

How to cite this article: Mutti LA, Mascarenhas MRM, Paiva JMG, Golcman R, Enokihara MY, Golcman B. Giant congenital melanocytic nevi: 40 years of experience with the serial excision technique. An Bras Dermatol. 2017;92(2):256-9. 